Resumo

\title{
Efeito agudo do Circuito Utilitário do Exército Brasileiro em marcadores cardiorrespiratórios de militares
}

Leandro Tavares Almeida Bsci, Rafael Melo MSci

Introdução: Nos mesmos parâmetros dos objetivos e características de execução do Treinamento de Resistência em Circuito, o Circuito Utilitário do Exercito Brasileiro é dividido em dez estações, cada uma com um tipo de exercício físico. Se o volume e a intensidade do treinamento forem exagerados e/ou tempo de recuperação insuficientes, podem ocorrer consequências danosas ao organismo. Portanto, é importante verificar as respostas cardiorrespiratórias relativas à carga do exercício, mesmo que agudamente.

Objetivo: Analisar se os efeitos agudos dos marcadores cardiorrespiratórios do treinamento em Circuito Utilitário do Exército Brasileiro encontram-se dentro dos limites de tolerância e segurança.

Métodos: A amostra foi composta por 10 militares do sexo masculino, alunos da Escola de Educação física do Exército (EsEFEx), saudáveis e fisicamente ativos, com idade média $27,8( \pm 1,69)$ anos, peso $77,44( \pm 8,40) \mathrm{kg}$ e altura $1,77( \pm 0,08)$ m. Os exercícios foram realizados em um espaço gramado, com o horário de coleta de dados entre 10 e 12 horas da manhã e foi respeitado um intervalo mínimo de $48 \mathrm{~h}$ entre a execução dos exercícios. Foram tomadas as frequências cardíacas de cada participante imediatamente antes do inicio do circuito, imediatamente após cada término de estação, um minuto após o final do circuito e, cinco minutos depois do término do circuito.

Resultados: Não houve diferenças estatísticas significantes entre as frequências cardíacas de pico medidas durante as execuções do circuito nos tempos de 30 , 45 e 60 segundos, $F(2,30)=0,5521, p=0,5872$.

Conclusão: Para o treinamento em Circuito Utilitário do Exercito Brasileiro, a variação dos volumes estudados não é fator determinante para se alcançar uma frequência de pico que corresponda à intensidade considerada "dura", estando na zona ideal de treinamento de um exercício físico. 